\title{
An Investigation on Surface and Electrical Properties of Electrical Discharge Machined AISI D2 Tool Steel
}

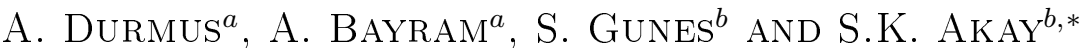 \\ ${ }^{a}$ Department of Mechanical Engineering, Faculty of Eng. and Arc., Uludag University, 16059 Bursa, Turkey \\ ${ }^{b}$ Department of Chemistry, Faculty of Sciences and Arts, Uludag University, 16059, Bursa, Turkey \\ The effects of pulse-on duration and finishing operation on the surface roughness and electrical resistivity of \\ AISI D2 tool steel machined by the electrical discharge machining process are investigated. Experimental results \\ indicate that surface roughness increased depending on the pulse-on duration. However, after the specific value, \\ surface roughness is decreased. It can be seen that there are no notable effects of the pulse-on duration on the \\ electrical resistivity, but the resistivity values are affected by the heat treatment and the finishing operation. Also, \\ light microscopy and scanning electron microscopy have been used to study the characteristics of the surfaces.
}

DOI: $10.12693 /$ APhysPolA.125.515

PACS: 52.80.-s, 81.65.-b

\section{Introduction}

Electrical discharge machining (EDM) which is a manufacturing process by which a tool cuts the required shape into the work piece within a dielectric fluid has been widely used in machining high hardness materials and alloys such as moulds/dies and aerospace industries. During machining, the discharge energy produces very high temperature at the point of the spark on the surface of the work piece, and removes the material by melting and vaporization. The advantage of EDM is that there is no direct contact between the electrode and the component during machining, and therefore no deformation occurs, even for thin components. Furthermore, this technique is capable of producing a fine, precise, corrosion-resistance and wear-resistance surface [1-3]. However, due to the rapid heating and cooling effects induced by the machining process, a thermally affected layer will form on the surface of the component. The structure of this layer is quite different from the parent material, and although it is beneficial in terms of enhanced abrasion and erosion resistance, the defects within it, such as voids, cracks, induced stresses etc. cause an overall deterioration of the component's mechanical properties [1]. This layer named re-cast or white layer in the literatures increases surface roughness, makes the surface become hard and brittle, and decreases the fatigue strength, corrosion and wear resistance of the work piece [3]. Therefore, several investigations are relevant to obtain a fine surface finish in accordance with effect of the machining parameters such as pulse current, pulse-on duration on the physical and mechanical properties of re-cast layer [4-6].

The thickness of recast layer is quietly small for surfaces machined with low pulse-on duration, such as

\footnotetext{
*corresponding author; e-mail: kakay@uludag.edu.tr
}

smaller than $1 \mu \mathrm{s}$. In that case, although the surface quality is better, the surface microhardness value of the re-cast layer cannot be measured as thickness of white layer is too small. The aim of the present work is investigated that there is a relationship between the resistivity value and the EDM process with heat treatment or not.

\section{Experimental procedure}

The work material used in the present investigation is the AISI D2 cold work tool steel $(1.428 \% \mathrm{C}$, $0.328 \% \mathrm{Mn}, \quad 11.231 \%$ Cr, $0.716 \%$ Mo, $0.852 \% \mathrm{~V}$, $0.320 \% \mathrm{Si}, 0.370 \% \mathrm{Ni}$, balanced $\mathrm{Fe}$ ). Mo-V alloy and high $\mathrm{C}-\mathrm{Cr}$ steel in this study came in the form of round bar with a diameter of $13 \mathrm{~mm}$. The initial material was heated to $1020^{\circ} \mathrm{C}$ with a heating rate $15^{\circ} \mathrm{C} \mathrm{min}-1$ in three steps. Then, the material was held at $1020^{\circ} \mathrm{C}$ for $75 \mathrm{~min}$ and was cooled down to $60^{\circ} \mathrm{C}$. Heat treatments are carried out on VUTK 524 Ipsen vacuum furnace. After this treatment, the material hardness is around $60 \pm 1 \mathrm{HRC}\left(728 \pm 16 \mathrm{HV}_{1}\right)$.

The EDM specimens were performed on a wire EDM machine model type Robofil 290P. Based on experience, literature survey, the primary parameters are pulsed current, time between two pulses, wire tension [7]. Because the pulse-on duration selected in this research is relatively smaller $(<1.1 \mu \mathrm{s})$, the investigation on the effect of the pulse-on duration is important for the rough cutting and finishing operation.

The surface roughness was measured using a TaylorHopson Surtronic $3+$. The cut-off and transverse length for each measurement were $0.8 \mathrm{~mm}$ and $4 \mathrm{~mm}$, respectively. Five cut-off lengths were measured on each specimen and their surface roughness was averaged. Optical micrographs of the cross-section of specimen were taken on an Olympus light microscope etching with $5 \%$ nital after grinding and polishing. The machined surfaces were examined using the scanning electron microscopy (SEM).

Electrical resistivity is one of the characteristic physical properties of materials and is dependent on temperature and on crystal defects, such as solute atoms, disloca- 
tions and impurities [8]. The electrical resistivity of the machined surfaces was measured by the four-point probe technique at room temperature. A Keithley 2400 source meter was used to provide constant current from 0.1 to $1 \mathrm{~A}$ and the potential was detected by a Keithley 2700 multimeter. A standard direct current four-point probe measurement is performed by making four electrical contacts to a circle shape samples. The electrical resistivity $\rho$ is determined by loading a direct current $I$, changing from 0.1 to $1 \mathrm{~A}$, through the outer pair of probes and measuring the voltage drop, $V$, between the inner pair of probes which are positioned at a distance of $D=1.2 \mathrm{~mm}$, using the following equation [9]:

$$
\rho=\frac{2 \pi D}{3} \frac{V}{I} \text {. }
$$

The electrical resistivity was recorded by calculating the average values of six measurements for each cutting parameter and specimen.

\section{Results and discussion}

The morphology of the surface which has undergone EDM is due to the amount of heat generated by the discharges, which causes melting and vaporization of the material, followed by rapid cooling [1]. As a result of this process, the surface roughness, $R_{\mathrm{a}}$ is increased generally. It is varied 2.5 to $3.3 \mu \mathrm{m}$ after machining for initial and heat treated material. The highest values were obtained at $0.9 \mu$ s pulse-on duration as $3.3( \pm 0.1) \mu \mathrm{m}$. Generally, it can be said that there are no notable differences be- tween the surface roughness of initial and heat treated material. The average $R_{\mathrm{a}}$ value of materials machined with finishing operation is $2.1( \pm 0.1) \mu \mathrm{m}$.

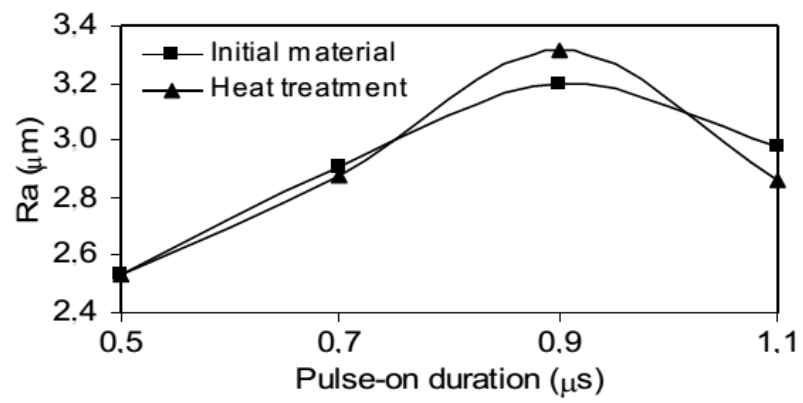

Fig. 1. The average surface roughness at different pulse-on durations.

The re-cast layer is formed by molten metal which is not flushed away by the dielectric, but resolidifies on the sample's machined surface during. The re-cast layer is composed mainly of martensite and retained austenite, with some dissolved carbide [1]. The optical micrographs given in Fig. 2 show damaged re-cast layer depending on the pulse duration for the initial and heat treated materials. Finishing operation is supplied to remove the re-cast layer and the rougher surface finish is left by the roughing operation.

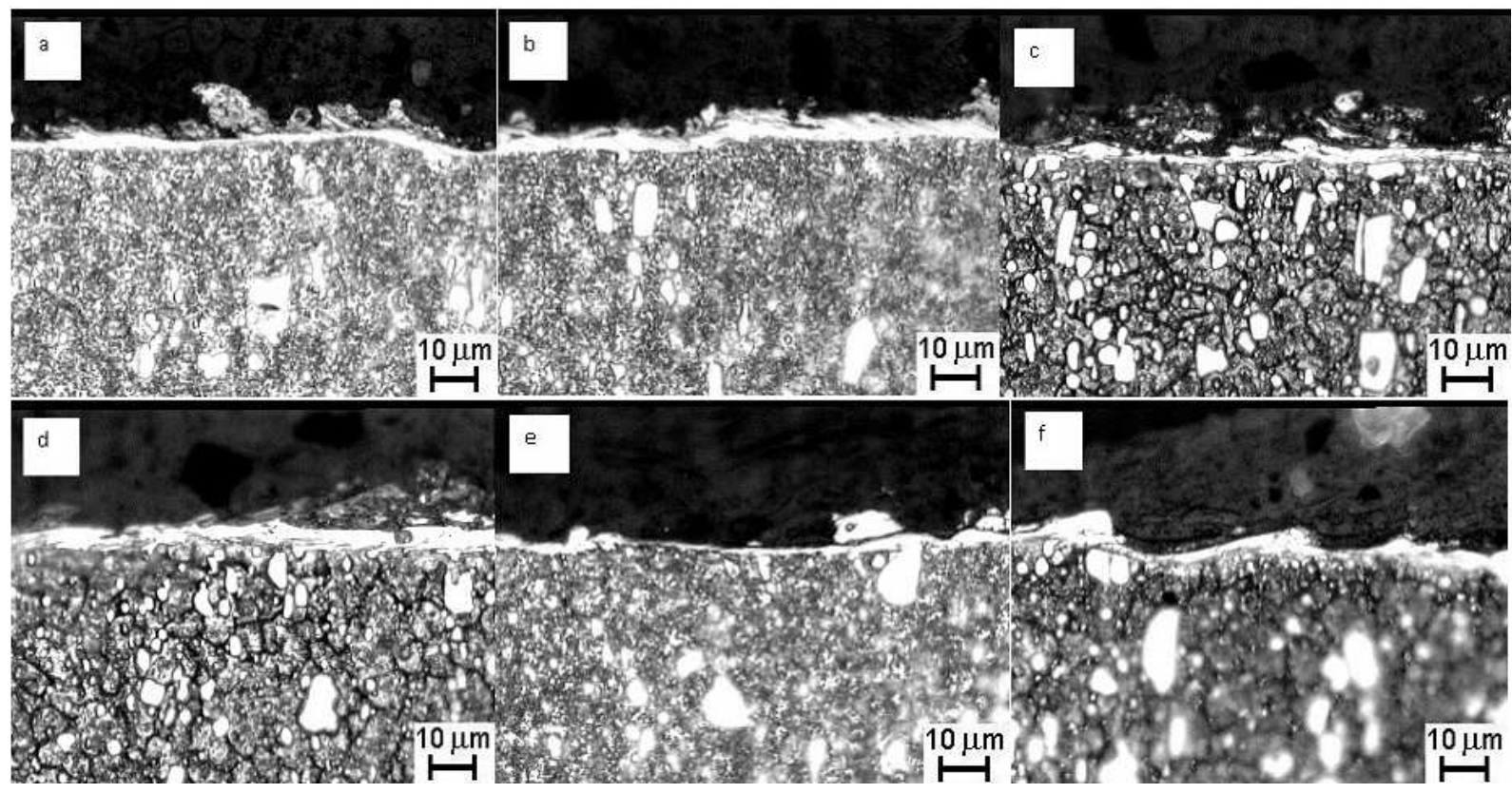

Fig. 2. Optical micrographs of cross-sections. Initial materials: (a) $0.5 \mu \mathrm{s}$, (b) $1.1 \mu \mathrm{s}$, heat treated materials: (c) $0.5 \mu \mathrm{s}$, (d) $1.1 \mu \mathrm{s}$, (e) and (f) finishing operation for initial and heat treated materials.

The electrical resistivity results of the samples were shown in Fig. 3 as a function of cutting method. It was observed that the resistivity values of the studied samples increase with the heat treatment procedures. The 
high value of the resistivity can be attributed to the dislocation and imperfections of the crystal structure of the samples. EDM processing increases the electrical resistivity on the heat treated material but it reduces the resistivity for initial material (Fig. 3). As the reason of the situation, it can be explained that temperature during the cutting reaches higher values comparing to original material, which has $226 \pm 5 \mathrm{HV}_{1}$ hardness, because of the high hardness value of heat treated material, such as $728 \pm 16 \mathrm{HV}_{1}$. It is known that the resistivity increases with material hardness [10].

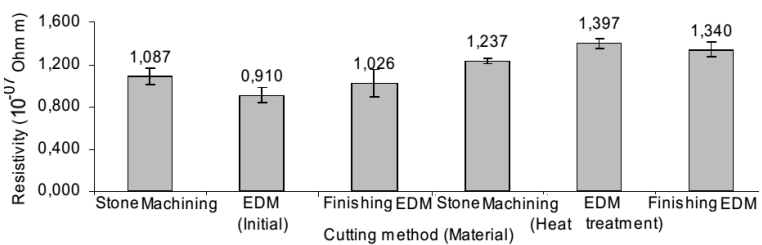

Fig. 3. Electrical resistivity versus machining method of materials.

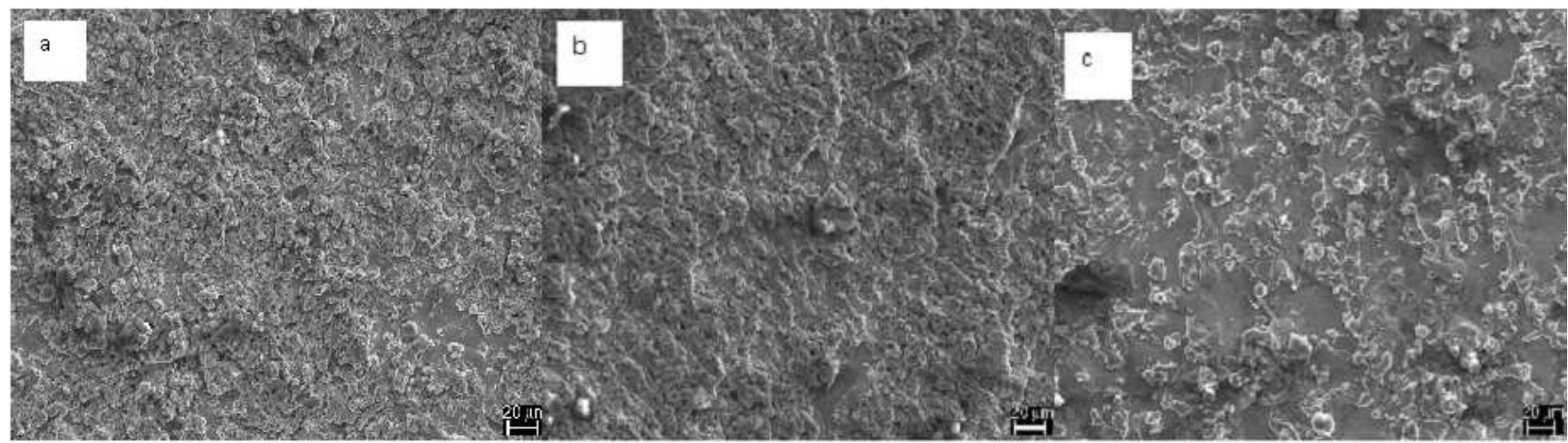

Fig. 4. SEM micrographs of the EDM surfaces. (a) Initial materials for pulse-on duration of $0.5 \mu$ s, (b) heat treated materials for pulse-on duration of $0.5 \mu \mathrm{s}$, and (c) finishing machined surfaces for initial and heat treated materials.

The machined surfaces are shown in Fig. 4 for the initial, heat treated, and finishing machined materials. It can be seen that EDM sparks erode surface randomly and the area of the eroded zones is decreased with the increase of the pulse-on duration. The crater size increases when the pulse-on duration is increased. For heat treated material, the crater dimensions are bigger than initial material's. The material removed is directly proportional to the quantity of energy applied during pulse on-time [11].

\section{Conclusion}

The present study shows that the surface roughness increases with the increase of the pulse-on duration, but it is decreased after specific value of pulse-on duration in case of use of the small pulse-on duration such as 0.5$0.9 \mu \mathrm{s}$. On the other hand, there are no notable effects of the pulse-on duration on the electrical resistivity. However, the resistivity values are affected by the heat treatment and EDM finishing operation.

\section{References}

[1] H.T. Lee, T.Y. Tai, J. Mater. Process. Technol. 142, 676 (2003).

[2] M.T. Yan, Y.P. Lai, Int. J. Mach. Tools Manufact. 47, 1686 (2007).
[3] Y.S. Liao, J.T. Huang, Y.H. Chen, J. Mater. Process. Technol. 149, 165 (2004).

[4] Y.H. Guu, H. Hocheng, C.Y. Chou, C.S. Deng, Mater. Sci. Eng. A 358, 37 (2003).

[5] M. Kiyak, O. Çakır, J. Mater. Process. Technol. 191, 141 (2007).

[6] H. Ramasawmy, L. Blunt, J. Mater. Process. Technol. 148, 155 (2004).

[7] T.A. Spedding, Z.Q. Wang, J. Mater. Process. Technol. 69, 18 (1997).

[8] J.S. Park, Y.K. Lee, Scr. Mater. 56, 225 (2007).

[9] W.R. Runyan, Semiconductor Measurements and Instrumentation, McGraw-Hill, Tokyo 1975.

[10] F. Sevini, B. Acosta, L. Debarberis, Int. J. Pressure Vessels Piping 83, 525 (2006).

[11] Ö. Salman, M.C. Kayacan, J. Mater. Process. Technol. 200, 347 (2008). 